\title{
Non-invasive Vagus Nerve Stimulation in Cerebral Stroke: Current Status and Future Perspectives
}

\author{
Lijuan Li1,2, Dong Wang ${ }^{3}$, Hongxia Pan ${ }^{1,2}$, Liyi Huang ${ }^{1,2}$, Xin Sun ${ }^{1,2}$, Chengqi He ${ }^{1,2}$ and \\ Quan Wei ${ }^{1,2 *}$
}

\begin{abstract}
${ }^{1}$ Rehabilitation Medicine Center and Institute of Rehabilitation Medicine, West China Hospital, Sichuan University, Chengdu, China, ${ }^{2}$ Key Laboratory of Rehabilitation Medicine in Sichuan Province, Sichuan University, Chengdu, China, ${ }^{3}$ Department of Rehabilitation Medicine, Affiliated Hospital of Chengdu University, Chengdu, China
\end{abstract}

\section{OPEN ACCESS}

Edited by:

Michele Giugliano, International School for Advanced

Studies (SISSA), Italy

Reviewed by: Stephen Silberstein,

Thomas Jefferson University,

United States

Stefan Kampusch,

SzeleSTIM GmbH, Austria

Anne Van Der Meij,

Leiden University Medical Center,

Netherlands

*Correspondence:

Quan Wei

weiquan@scu.edu.cn

Specialty section:

This article was submitted to

Neural Technology,

a section of the journal

Frontiers in Neuroscience

Received: 23 November 2021

Accepted: 25 January 2022

Published: 16 February 2022

Citation:

Li L, Wang D, Pan H, Huang L,

Sun X, He C and Wei Q (2022)

Non-invasive Vagus Nerve Stimulation in Cerebral Stroke: Current Status

and Future Perspectives.

Front. Neurosci. 16:820665.

doi: 10.3389/fnins.2022.820665
Stroke poses a serious threat to human health and burdens both society and the healthcare system. Standard rehabilitative therapies may not be effective in improving functions after stroke, so alternative strategies are needed. The FDA has approved vagus nerve stimulation (VNS) for the treatment of epilepsy, migraines, and depression. Recent studies have demonstrated that VNS can facilitate the benefits of rehabilitation interventions. VNS coupled with upper limb rehabilitation enhances the recovery of upper limb function in patients with chronic stroke. However, its invasive nature limits its clinical application. Researchers have developed a non-invasive method to stimulate the vagus nerve (non-invasive vagus nerve stimulation, nVNS). It has been suggested that nVNS coupled with rehabilitation could be a promising alternative for improving muscle function in chronic stroke patients. In this article, we review the current researches in preclinical and clinical studies as well as the potential applications of nVNS in stroke. We summarize the parameters, advantages, potential mechanisms, and adverse effects of current nVNS applications, as well as the future challenges and directions for nVNS in cerebral stroke treatment. These studies indicate that nVNS has promising efficacy in reducing stroke volume and attenuating neurological deficits in ischemic stroke models. While more basic and clinical research is required to fully understand its mechanisms of efficacy, especially Phase III trials with a large number of patients, these data suggest that nVNS can be applied easily not only as a possible secondary prophylactic treatment in chronic cerebral stroke, but also as a promising adjunctive treatment in acute cerebral stroke in the near future.

Keywords: non-invasive vagus nerve stimulation, transcutaneous cervical VNS, transcutaneous auricular VNS, rehabilitation, stroke, parameters

\section{INTRODUCTION}

It is estimated that there will be approximately 200 million stroke patients in the world by 2050 (Brainin et al., 2020). Despite extensive therapeutic advances in recent years, stroke including ischemic and hemorrhagic (roughly 87 and 13\%) (Kuriakose and Xiao, 2020), is still a leading cause of disability and a significant health problem worldwide. Approximately $60 \%$ of patients who suffer 
stroke only partially recover or are unable to recover within 6 months (Lee et al., 2015). Therefore, it is paramount to develop novel complementary treatment approaches that can be easily applied and do not interfere with established protocols including thrombolysis and thrombectomy.

During stroke rehabilitation, developing effective and evidence-based therapies to reduce impairment, improve functional activities, and enhance participation in activities are important goals. Neurostimulation techniques have been used increasingly in clinical and fundamental neuroscience. Vagus nerve stimulation (VNS), a Food and Drug Administration (FDA)-approved addition to medication for the treatment of partial epilepsy, depression, and primary headache disorders, is one potential therapy (Ben-Menachem, 2002; Yuan and Silberstein, 2016; Carreno and Frazer, 2017). It has also recently been recognized that VNS has the potential to enhance the recovery from neurological injuries, including stroke (Khodaparast et al., 2014, 2016; Capone et al., 2017; Dawson et al., 2021). The VNS-REHAB study, which was recently published in the Lancet, supports the use of VNS as a new therapeutic option for limb paralysis caused by an ischemic stroke (Dawson et al., 2021). In clinical practice, two methods of stimulation are used: invasive vagus nerve stimulation (iVNS) and non-invasive vagus nerve stimulation (nVNS) (Mertens et al., 2018; Wang et al., 2021c). nVNS are noninvasive devices that have been developed to stimulate the vagus nerve transcutaneously. By which, unique risks and adverse events associated with implants such as medical care, infection, peritracheal hematoma, damaged vocal cords, and dyspnea are precluded or reduced (Ben-Menachem et al., 2015; Zhao X.-P. et al., 2019; Li et al., 2020b). Furthermore, nVNS delivery systems may be more suitable for emergency patients who have suffered bursts of ischemic stroke. These systems may not require a surgical procedure, thereby improving patient safety.

As nVNS continues to rapidly grow in popularity and application in stroke, the field generally lacks a consensus on optimum initial time, stimulation cites, and stimulation parameters. The question of whether the nVNS can have the same effects in stroke recovery, as well as the underlying mechanisms and future research directions, needs to be addressed further. Therefore, this critical review aims to explore the reported studies on nVNS in stroke to present narrative accounts of its therapeutic potential and mechanisms of action that may facilitate its therapeutic effects. The abbreviations in this review are listed in Table $\mathbf{1 .}$

\section{VAGUS NERVE STIMULATION}

\section{History and Clinical Application of Vagus Nerve Stimulation}

Vagus nerve stimulation has a history dating back to the 19th century when James Corning examined the anti-seizure effect of manual stimulation of the vagal nerve in epileptic patients (Lanska, 2002). There are two methods of stimulation in clinical practice, invasive vagus nerve stimulation (iVNS) and non-invasive vagus nerve stimulation (nVNS). According to an international consensus published recently, there are four
TABLE 1 | Abbreviations

\begin{tabular}{|c|c|c|c|}
\hline \multicolumn{4}{|l|}{ Abbreviations } \\
\hline Auricular branch of the vagal nerve & ABVN & $\begin{array}{l}\text { Middle cerebral artery } \\
\text { occlusion }\end{array}$ & MCAO \\
\hline Autonomic nervous system & ANS & Myeloperoxidase & MPO \\
\hline Blood brain barrier & $\mathrm{BBB}$ & $\begin{array}{l}\text { Non-invasive vagus } \\
\text { nerve stimulation }\end{array}$ & nVNS \\
\hline Blood oxygen level dependent & BOLD & Non-invasive VNS & nVNS \\
\hline Brain-derived neurotrophic factor & BDNF & Norepinephrine & $\mathrm{NE}$ \\
\hline Central nervous system & CNS & $\begin{array}{l}\text { Nucleus tractus } \\
\text { solitarious }\end{array}$ & NTS \\
\hline $\begin{array}{l}\text { Cholinergic anti-inflammatory } \\
\text { pathway }\end{array}$ & CAP & $\begin{array}{l}\text { Percutaneous auricular } \\
\text { VNS }\end{array}$ & paVNS \\
\hline Dentate gyrus & DG & $\begin{array}{l}\text { Peroxisome } \\
\text { proliferator-activated } \\
\text { receptor } \gamma\end{array}$ & PPAR $\gamma$ \\
\hline Dynamic contrast enhanced MRI & DCE-MRI & Post-stroke insomnia & $\mathrm{PSI}$ \\
\hline Electromyogram & EMG & $\begin{array}{l}\text { Spreading } \\
\text { depolarization }\end{array}$ & SD \\
\hline Endothelial nitric oxide synthase & eNOS & Tight junction protein & TJP \\
\hline Food and Drug Administration & FDA & $\begin{array}{l}\text { Transcutaneous } \\
\text { auricular vagus nerve } \\
\text { stimulation }\end{array}$ & taVNS \\
\hline $\begin{array}{l}\text { Fugl-meyer assessment-upper } \\
\text { extremity }\end{array}$ & FMA-UE & $\begin{array}{l}\text { Transcutaneous } \\
\text { cervical vagus nerve } \\
\text { stimulation }\end{array}$ & tcVNS \\
\hline Function independent measure & FIM & $\begin{array}{l}\text { Transcutaneous vagus } \\
\text { nerve stimulation }\end{array}$ & tVNS \\
\hline $\begin{array}{l}\text { Functional magnetic resonance } \\
\text { imaging }\end{array}$ & fMRI & Traumatic brain injury & $\mathrm{TBI}$ \\
\hline Growth differentiation factor 11 & GDF11 & Tumor necrosis factor $\alpha$ & $\mathrm{TNF}-\alpha$ \\
\hline Human high mobility group 1 & HMGB1 & Upper limb fugl-meyer & UFM \\
\hline $\begin{array}{l}\text { Hypothalamic-pituitary-adrenal } \\
\text { axis }\end{array}$ & HPA & Vagus nerve & VN \\
\hline Interleukin & $\mathrm{IL}$ & Vagus nerve stimulation & VNS \\
\hline Invasive vagus nerve stimulation & iVNS & $\begin{array}{l}\text { Vascular endothelial } \\
\text { growth factor }\end{array}$ & VEGF \\
\hline Ischemia/reperfusion & $\mathrm{l} / \mathrm{R}$ & $\begin{array}{l}\text { Wolf motor function } \\
\text { test }\end{array}$ & WMFT \\
\hline Matrix metalloproteinase & MMP & $\begin{array}{l}\alpha 7 \text { nicotinic } \\
\text { acetylcholine receptor }\end{array}$ & $\alpha 7 n A c h R$ \\
\hline
\end{tabular}

currently accepted VNS modalities: cervically implanted VNS (iVNS), transcutaneous cervical VNS (tcVNS), transcutaneous auricular VNS (taVNS), percutaneous auricular VNS (paVNS) (Farmer et al., 2020). In iVNS, a pulse generator is implanted beneath the skin in the upper chest, along with electrodes connected to the left vagal nerve (Goodnick et al., 2001; Pruitt et al., 2016; Dawson et al., 2021). Systems for delivering nVNS utilize the distribution of vagal afferents through the skin, either at the external ear (taVNS) or in the neck (tcVNS) (Straube et al., 2015; Gaul et al., 2016; Genheimer et al., 2017; Burger et al., 2019).

Following decades of trials conducted on animals and humans. iVNS was approved by the FDA for the treatment of medically refractory partial epilepsy in 1997 (Morris et al., 2013) and severe, recurrent unipolar depression and bipolar depression in 2005 (Young et al., 2020). iVNS Therapy also received Conformite Europeenne (CE) marking in Europe for the treatment of epilepsy and treatment-resistant or 
treatment-intolerant depression (DeGiorgio and Krahl, 2013; Young et al., 2020). Invasive surgeries and their unwanted side effects of iVNS have led to the development of a new, completely non-invasive stimulation way. nVNS has received special attention from basic, clinical, and translational studies due to its comparable benefits to iVNS, ease of use, higher accessibility, and fewer side effects (Ben-Menachem et al., 2015; Frangos et al., 2015; Marin et al., 2018). nVNS entered clinical treatment in 1997, its clinical effectiveness and its physiological action are similar but with greater tolerability and fewer patients reporting side effects (Redgrave J. et al., 2018). tcVNS has also been approved by the FDA to treat migraines (Martelletti et al., 2018) and cluster headaches (Gaul et al., 2016; Marin et al., 2018).

In such a long period of clinical practice, hundreds of thousands of patients have been treated for various neurological disorders, such extensive experience has provided many opportunities to explore new clinical applications for VNS in other neuropsychiatric disorders except epilepsy, migraines, depression. And Among the most intriguing potential directions of VNS is the treatment of stroke. Recent randomized controlled trials have also shown that combined with rehabilitation therapy, iVNS and nVNS may benefit upper limb recovery after stroke (Khodaparast et al., 2014; Capone et al., 2017; Dawson et al., 2021).

\section{Anatomic Basis for Non-invasive Vagus Nerve Stimulation}

The vagus nerve (VN) is a mixed cranial nerve composed of $80 \%$ sensory fibers (afferent) and 20\% motor fibers (efferent). It is located on both the left and right sides of the body, acting as a two-way channel between the central nervous system and the autonomic nervous system (ANS), transmitting sensory and motor information between the systems. Its afferent fibers transmit visceral and somatic information from the body to the brainstem and thus providing a unique pathway to the brain (Groves and Brown, 2005; Kaniusas et al., 2019; Farmer et al., 2020). While its efferent fibers originate in the dorsal motor nucleus (to supply the heart, lungs, esophagus, and stomach) and in the nucleus ambiguous (to innervate the muscles in pharynx and larynx). Most of afferent fibers of VN terminate in the nucleus tractus solitarius (NTS) in the lower medulla (e.g., for visceral afferents, heart, taste, and aorta), whereas others terminate in the nucleus spinalis of the trigeminal nerve, like some laryngeal and pharyngeal afferents (Trevizol et al., 2015; Yuan and Silberstein, 2016). The right part of the vagus nerve is more closely associated with the cardiac atria and innervates the sinoatrial node that controls heart rate; whereas the left part of the vagus nerve is typically associated with the ventricles of the heart and innervates the atrioventricular node that controls contraction force (Guiraud et al., 2016). The vagus nerve is therefore essential in the maintenance of homeostasis and parasympathetic system function, regulating inflammatory, cardiovascular function, and gastric emptying efferent effects.

According to Erlanger and Gasser, the VN consists of A-, B-, and $\mathrm{C}$-fibers with corresponding conduction velocities (Yuan and
Silberstein, 2016). Based on anatomical research, as the VN passes caudally through their ganglia, it divides into four branches: the auricular branch, the meningeal branch, the sympathetic branch (joint with the superior cervical sympathetic ganglion), the pharyngeal branch, and the laryngeal branch (Ruffoli et al., 2011; Yuan and Silberstein, 2016; Kaniusas et al., 2019). The auricular branch of the vagus nerve (ABVN) is the only branch of vagus nerve that reaches the body surface. As the ABVN forms a cutaneous receptive field in the pinna, which is roughly located in the 1-1.5 mm gap between the skin and the auricular cartilage (Bermejo et al., 2017). ABVN can be found in both the cymba and cavum conchae, however, cymba conchae are $100 \%$ dominated by ABVN (Peuker and Filler, 2002). The ABVN afferent fiber enters the vagal trunk via the jugular ganglion and projects NTS, where the integration of autonomic neurons occurs. The conchae collect afferent information and activate the caudal ventrolateral medulla and dorsal motor nucleus to control central autonomic activity (Butt et al., 2020; Wang et al., 2021b). This is why the conchae have the ability to manage bodily functions. Yakunina et al. (2017) found that stimulation of the auricular canal could activate the vagus nerve pathway to the maximum extent, so this location might be the best anatomical location for transcutaneous vagus nerve stimulation.

During the first half of the twentieth century, researchers began studying the NTS of the vagus nerve, the main afferent transmission from the vagus nerve to the central nervous system, and its projections to the cortex. The areas of the brain that are activated by $\mathrm{nVNS}$ depending on the focus have been speculated in various studies. Empirical measures, such as fMRI, EEG, and MEG, are critical to confirm proposed hypotheses (SchulzStübner and Kehl, 2011; Colzato et al., 2018; Jongkees et al., 2018). Burger and Verkuil (2018) suggest that nVNS engages limbic areas, such as the hippocampal and amygdala, while Yuan and Silberstein (2016) suggest that stimulation of the vagus nerve influences the distribution of hypocretin and orexin in people with cluster headache, and Jacobs et al. (2015) suggest that nVNS enhances memory by increasing locus coeruleus activity. With fMRI. Kraus et al. (2007) demonstrated that non-invasive vagus nerve stimulation results in prominent changes in cerebral activity with marked deactivation in temporal and limbic regions. fMRI studies have shown that nVNS increases neural activity more than sham stimulation in the left prefrontal cortex, right caudate, mid-cingulate and cerebellum (Badran et al., 2018). It also decreases functional connectivity between the posterior cingulate cortex and the lingual gyrus (Zhao B. et al., 2019), and suppresses processes to generate tinnitus (Yakunina et al., 2018; Yakunina and Nam, 2021).

Stimulation of the vagus nerve may also increase synaptic plasticity in central networks after injury (Meyers et al., 2018; Collins et al., 2021). When the vagus nerve is stimulated electrically, the neuromodulatory effect is immediately triggered. A VNS pulse rapidly activates noradrenergic locus coeruleus and cholinergic nucleus basalis, two key neuromodulators in the brain (Morrison et al., 2021). When these pro-plasticity neuromodulators are simultaneously released with neural activity related to rehabilitation, synaptic plasticity in task-specific circuits is promoted. 
In general, VN activity correlates with wellbeing, health, relaxation, and even emotions like empathy, while it is negatively correlated with risk factors such as morbidity, mortality, and stress (Thayer et al., 2010; Zulfiqar et al., 2010; Farmer et al., 2020). VN thus plays a critical role in brain-body interactions. These complex interactions naturally cause interest in artificial stimulation for therapeutic purposes.

\section{NON-INVASIVE VAGUS NERVE STIMULATION IN ANIMAL MODELS OF STROKE}

In the review of nine animal studies (Ay et al., 2016; Jiang et al., 2016; Ma et al., 2016; Yang et al., 2018; Zhao X.-P. et al., 2019; Li et al., 2020b,a; Lindemann et al., 2020; Zhao et al., 2022; Table 2), most manuscripts have settled on a frequency of 20 or $25 \mathrm{~Hz}$ that has been shown to be more biologically active both in implanted functional neuroimaging as well as in taVNS optimization trials (Raedt et al., 2011; Hays et al., 2014; Thompson et al., 2021). The FDA approved areas of 20 to $30 \mathrm{~Hz}$ stimulation frequencies because studies had shown that frequencies of $50 \mathrm{~Hz}$ and above can cause severe and irreversible damage to the vagus nerve during VNS (Groves and Brown, 2005). Table 2 shows that three studies used the cervical branch of the vagus nerve and six studies used the ABVN as stimulation locations. In rodent models, although the lateral differences are not clear and may differ depending on the parameters used, most of these studies used the left vagus nerve for stimulation.

The tcVNS was initiated at variable times $(30 \mathrm{~min}$ to $24 \mathrm{~h}$ ) after cerebral ischemia in rats and mice. The ability of tcVNS to activate the NTS was assessed using c-Fos immunohistochemistry. tcVNS activates the vagus nerve fibers and stimulates its main afferent relay nuclei in the brainstem (NTS) (Ay et al., 2016). The main effects and mechanisms of nVNS illuminated in animal research are summarized below.

\section{Reducing Infarct Size and Improving Neurological Outcome}

Several animal studies have demonstrated that nVNS could reduce the cerebral infarction volume and improve the neurological deficit remarkably in rats with cerebral ischemia (Ay et al., 2016; Zhao X.-P. et al., 2019; Li et al., 2020b; Lindemann et al., 2020; Zhao et al., 2022). In these studies, nVNS provided approximately a $25-50 \%$ reduction in infarct size, which was similar to previously reported reductions achieved by iVNS (Ay et al., 2011; Sun et al., 2012). Ay et al. (2016) tested the effect of tcVNS at different initiated time after middle cerebral artery occlusion (MCAO) on tissue and functional outcome by changing the therapeutic window up and down by $1 \mathrm{~h}$ each time until a comparable effect size with 30 -min stimulation was achieved. They found that the effect of tcVNS on infarct size was consistent when stimulation was initiated up to $4 \mathrm{~h}$ after MCAO. Furthermore, the improvement in forelimb function was so longlasting that it continued even after the stimulation had stopped, consistent with results obtained in aged ischemic stroke rats treated with iVNS and rehabilitative training (Hays et al., 2016).

\section{Promoting Angiogenesis}

After focal cerebral ischemia, the newly formed collateral blood vessels can improve perfusion of the surrounding tissues and promote recovery of nervous system functions. Recent studies have suggested that angiogenesis, almost in parallel to neurogenesis, participates in the recovery of neurological function after ischemic stroke (Song et al., 2019; Alrafiah et al., 2021; Wang et al., 2021a). It was proposed that VNS increased hippocampal progenitor cell proliferation in the adult rat dentate gyrus, so that such progenitor cells contribute to the healing of damaged neurons from ischemic injury ( $\mathrm{Lu}$ et al., 2017). It would appear that this plasticity is involved in VNS's efficacy as a treatment for ischemic stroke. In cerebral ischemic rats, taVNS enhanced the expression of angiogenic factors, including BDNF, eNOS, and VEGF, and increased endothelial proliferation, stimulated angiogenesis, and increased microvessel density surrounding the infarct area (Zhang et al., 2017). Another study has shown that taVNS promotes endothelial cells proliferation 7 days after cerebral ischemia, and that taVNS enhances expression of ALK5 in endothelial cells (Ma et al., 2016). The effects of taVNS on poststroke recovery, as well as up-regulation of cerebral GDF11, and down-regulation of splenic GDF11, indicate brain-spleen communication. Following a stroke, the brain releases ischemic signals, the activated spleen released its GDF11 reserves into the blood circulation, allowing it to deposit in the damaged brain. These results indicate that taVNS may enhance the recovery after stroke by increasing GDF11 concentrations in the vasculature (Ma et al., 2016).

\section{Regulating Blood Brain Barrier Permeability}

The breakdown of the Blood Brain Barrier (BBB) and the subsequent brain edema are two of the key components of neurological dysfunction in stroke. They are associated with poor clinical outcomes during and after ischemic stroke (Cai et al., 2014). A significant association between stroke progression and $\mathrm{BBB}$ breakdown has been demonstrated. As early $\mathrm{BBB}$ permeability can be reversed with treatment, it would make sense that the VNS could be involved in regulating cerebral edema after stroke (Gaul et al., 2016).

According to a study, the use of taVNS during MCAO significantly reduced the permeability of the BBB after ischemia and reperfusion measured by DCE-MRI $24 \mathrm{~h}$ after stroke. taVNS treated rats with ischemic hemispheres demonstrated significantly lower levels of serum IgG leakage as detected by IHC after MRI, consistent with the findings described above (Yang et al., 2018). BBB integrity is maintained primarily by ECs sealed at tight junctions, astrocyte endfeet, pericytes, and extracellular matrix. In reperfusion injury, proteases are involved in the biphasic opening of the BBB. A number of mechanisms have been proposed to account for the degradation 
TABLE 2 | Stimulation location, parameters, and therapeutic effects for all studies of nVNS in rodent models of stroke.

\begin{tabular}{|c|c|c|c|c|c|c|c|c|}
\hline Authors & $\begin{array}{l}\text { Rodent } \\
\text { models }\end{array}$ & Device & $\begin{array}{l}\text { Initial } \\
\text { time }\end{array}$ & Parameters & $\begin{array}{c}\text { Stimulation } \\
\text { side and sites }\end{array}$ & $\begin{array}{l}\text { Stimulation } \\
\text { duration }\end{array}$ & Effects & $\begin{array}{l}\text { Results and } \\
\text { conclusion }\end{array}$ \\
\hline $\begin{array}{l}\text { Zhao et al., } \\
2022\end{array}$ & $\begin{array}{c}\text { Rat, l/R (right } \\
\text { ICA) }\end{array}$ & $\begin{array}{c}\text { taVNS, tcvns } \\
\text { (Hanshi } \\
\text { Electroacupuncture } \\
\text { Instrument, Nanjing } \\
\text { Hanshi Co. Ltd.) }\end{array}$ & $\begin{array}{l}24 \mathrm{~h} \\
\text { post- } \\
\text { stroke }\end{array}$ & $\begin{array}{c}10 \mathrm{~Hz}, 1 \mathrm{~mA} \text {, Pulse } \\
\text { width (not } \\
\text { described) }\end{array}$ & $\begin{array}{c}\text { Bilateral concha } \\
\text { auricularis } \\
\text { region or rat } \\
\text { tragus }\end{array}$ & $\begin{array}{c}30 \mathrm{~min} / \text { session, } \\
7 \text { days }\end{array}$ & $\begin{array}{c}\text { Levels of } \\
\text { acetylcholine, IL-1 } \\
\text { IL-6, and TNF- } \alpha \downarrow \text {; } \\
\text { Cx43 } \\
\text { phosphorylation } \downarrow\end{array}$ & $\begin{array}{l}\text { Improves motor } \\
\text { function }\end{array}$ \\
\hline $\begin{array}{l}\text { Li et al., } \\
2020 a\end{array}$ & $\begin{array}{l}\text { Rats, } \mathrm{MCAO} / \mathrm{R} \\
\text { (right) }\end{array}$ & $\begin{array}{c}\text { taVNS (Grass } \\
\text { Model S48 } \\
\text { stimulator, Grass } \\
\text { Technologies, } \\
\text { Warwick, } \\
\text { United States) }\end{array}$ & $\begin{array}{l}30 \text { min } \\
\text { post- } \\
\text { stroke }\end{array}$ & $\begin{array}{c}20 \mathrm{~Hz}, 0.5 \mathrm{~mA} \text {, } \\
0.5 \mathrm{~ms} \text {, square } \\
\text { wave }\end{array}$ & $\begin{array}{l}\text { Left cavum } \\
\text { concha }\end{array}$ & $\begin{array}{l}60 \mathrm{~min} / \text { session, } \\
\text { twice daily, } \\
14 \text { days, } \\
28 \text { days }\end{array}$ & $\begin{array}{c}\text { PPAR- } \gamma \downarrow ; \\
\text { BDNF, VEGF, } \\
\text { P-eNOS } \uparrow\end{array}$ & $\begin{array}{c}\text { Decreases } \\
\text { neurological deficit } \\
\text { scores, neuronal } \\
\text { damage, and infarct } \\
\text { volume. Increases } \\
\text { microvessel density } \\
\text { and endothelial cell } \\
\text { proliferation. }\end{array}$ \\
\hline $\begin{array}{l}\text { Lindemann } \\
\text { et al., } 2020\end{array}$ & $\begin{array}{l}\text { Rats, MCAO } \\
\text { (left) }\end{array}$ & $\begin{array}{l}\text { tcVNS, iVNS } \\
\text { (External } \\
\text { transcutaneous } \\
\text { stimulator, } \\
\text { electrocore Inc.) }\end{array}$ & $\begin{array}{l}30 \text { min } \\
\text { post- } \\
\text { stroke }\end{array}$ & $\begin{array}{c}\text { iVNS: } 25 \mathrm{~Hz} \\
0.5 \mathrm{~mA}, 0.3 \mathrm{~ms} \\
\text { tcVNS: } 25 \mathrm{~Hz}, 1 \mathrm{~ms} \text {, } \\
5 \mathrm{kHz} \text { sine waves. }\end{array}$ & $\begin{array}{c}\text { Left vagus } \\
\text { nerve (ivns), left } \\
\text { cervical vagus } \\
\text { nerve (tcvns) }\end{array}$ & $\begin{array}{l}\text { iVNS: } 60 \mathrm{~min} \\
\text { tcVNS: } 2 \text { min, } \\
\text { repeated after } \\
\quad 15 \text { min }\end{array}$ & $\begin{array}{c}\text { Spreading } \\
\text { depolarizations } \\
\text { frequency } \downarrow\end{array}$ & $\begin{array}{l}\text { Improves behavioral } \\
\text { tests. Reduces } \\
\text { infarct volume. Both } \\
\text { iVNS and nVNS } \\
\text { reduce the } \\
\text { frequency of SDs. }\end{array}$ \\
\hline $\begin{array}{l}\text { Li et al., } \\
2020 b\end{array}$ & $\begin{array}{c}\text { Rats, } \mathrm{MCAO} / \mathrm{R} \\
\text { (right) }\end{array}$ & $\begin{array}{c}\text { taVNS } \\
\text { (Grass Model S48 } \\
\text { stimulator, Grass } \\
\text { Technologies, } \\
\text { Warwick, } \\
\text { United States) }\end{array}$ & $\begin{array}{l}30 \mathrm{~min} \\
\text { post- } \\
\text { stroke }\end{array}$ & $\begin{array}{l}20 \mathrm{~Hz}, 0.5 \mathrm{MA} \text {, } \\
0.5 \mathrm{~ms} \text {, square }\end{array}$ & $\begin{array}{l}\text { Left cavum } \\
\text { concha }\end{array}$ & $\begin{array}{c}60 \text { min/session, } \\
\text { twice } \\
\text { daily, } 14 \text { days, } \\
28 \text { days }\end{array}$ & $\begin{array}{c}\alpha 7 n A c h R \\
\text { expression } \downarrow ; \\
\text { Activation of the } \\
\text { BDNF/cAMP/PKA/p- } \\
\text { CREB } \\
\text { pathway }\end{array}$ & $\begin{array}{l}\text { Enhance axonal } \\
\text { plasticity through } \\
\text { activation of the } \\
\text { BDNF/cAMP/PKA/p- } \\
\text { CREB } \\
\text { pathway }\end{array}$ \\
\hline $\begin{array}{l}\text { Zhao X.-P. } \\
\text { et al., } 2019\end{array}$ & $\begin{array}{c}\text { Mice, } \\
\text { MCAO/R (right) }\end{array}$ & $\begin{array}{c}\text { tcVNS } \\
\text { (gammacore; } \\
\text { Lectrocore, LLC, } \\
\text { Basking Ridge, NJ, } \\
\text { United States) }\end{array}$ & $\begin{array}{c}1 \mathrm{~d} \\
\text { before } \\
\text { MCAO }\end{array}$ & $\begin{array}{c}25 \mathrm{~Hz}, 1 \mathrm{~ms}, 5 \mathrm{kHz} \\
\text { sinewaves } \\
\text { average voltage } \\
\text { of } 15 \mathrm{~V}\end{array}$ & $\begin{array}{l}\text { Right cervical } \\
\text { vagus nerve }\end{array}$ & $60 \mathrm{~min}$ & $\begin{array}{c}\text { M2 phenotype } \\
\text { microglia : Arg- } 1^{+} \\
\text {cells } \uparrow ; \text { IL-17A } \downarrow ; \\
\text { (TUNEL }+ \text { NeuN }+ \text { ) } \\
\text { cells } \downarrow\end{array}$ & $\begin{array}{c}\text { Reduces infarct } \\
\text { volume. Improves } \\
\text { neurological } \\
\text { outcomes. } \\
\text { Reduces neurons } \\
\text { apoptosis. Promotes } \\
\text { microglial M2 } \\
\text { polarization. }\end{array}$ \\
\hline $\begin{array}{l}\text { Yang et al., } \\
2018\end{array}$ & $\begin{array}{l}\text { Rats, MCAO } \\
\text { (right) }\end{array}$ & $\begin{array}{c}\text { taVNS } \\
\text { (gammacore; } \\
\text { Lectrocore, LLC, } \\
\text { Basking Ridge, NJ, } \\
\text { United States) }\end{array}$ & $\begin{array}{l}30 \text { min } \\
\text { post- } \\
\text { stroke }\end{array}$ & $\begin{array}{c}25 \mathrm{~Hz}, 1 \mathrm{~ms}, 5 \mathrm{kHz} \\
\text { sinewaves } \\
\text { average voltage } \\
\text { of } 15 \mathrm{~V}\end{array}$ & $\begin{array}{l}\text { Left cervical } \\
\text { vagus nerve }\end{array}$ & $50 \mathrm{~min}$ & $\begin{array}{c}\text { TJPs: ZO- } 1 \uparrow \\
\text { BBB transfer rate, } \\
\text { serum IgG leakage } \downarrow ; \\
\text { MMP- } 2 / 9 \downarrow\end{array}$ & $\begin{array}{c}\text { Reduces infarct } \\
\text { volume. Protects } \\
\text { Blood-brain barrier. }\end{array}$ \\
\hline $\begin{array}{l}\text { Ma et al., } \\
2016\end{array}$ & $\begin{array}{c}\text { Rats, } \mathrm{MCAO} / \mathrm{R} \\
\text { (right) }\end{array}$ & $\begin{array}{c}\text { taVNS } \\
\text { (Grass Model S48 } \\
\text { stimulator, Grass } \\
\text { Technologies, } \\
\text { Warwick, } \\
\text { United States) }\end{array}$ & $\begin{array}{l}30 \text { min } \\
\text { post- } \\
\text { stroke }\end{array}$ & $\begin{array}{l}20 \mathrm{~Hz}, 0.5 \mathrm{~mA} \text {, } \\
0.5 \mathrm{~ms} \text {, square }\end{array}$ & $\begin{array}{l}\text { Left cavum } \\
\text { concha }\end{array}$ & $\begin{array}{l}60 \mathrm{~min} / \text { session, } \\
\text { twice daily, } 24 \mathrm{~h}, \\
3 \text { days, } 7 \text { days }\end{array}$ & $\begin{array}{l}\text { upregulate cerebral } \\
\text { GDF11 and } \\
\text { downregulate splenic } \\
\text { GDF11; increase } \\
\text { expression of ALK5 in } \\
\text { ECs; stimulate } \\
\text { proliferation of ecs. }\end{array}$ & $\begin{array}{c}\text { Prompts neuro } \\
\text { behavioral recovery } \\
\text { Stimulated } \\
\text { proliferation of } \\
\text { endothelial cells. }\end{array}$ \\
\hline $\begin{array}{l}\text { Jiang et al., } \\
2016\end{array}$ & $\begin{array}{c}\text { Rats, } \mathrm{MCAO} / \mathrm{R} \\
\text { (right) }\end{array}$ & $\begin{array}{c}\text { taVNS } \\
\text { (Grass Model S48 } \\
\text { stimulator, Grass } \\
\text { Technologies, } \\
\text { Warwick, } \\
\text { United States) }\end{array}$ & $\begin{array}{l}30 \text { min } \\
\text { post- } \\
\text { stroke }\end{array}$ & $\begin{array}{l}20 \mathrm{~Hz}, 0.5 \mathrm{~mA}, \\
0.5 \mathrm{~ms} \text {, square }\end{array}$ & $\begin{array}{l}\text { Left cavum } \\
\text { concha }\end{array}$ & $\begin{array}{c}60 \mathrm{~min} / \text { session, } \\
\text { 2-3 weeks }\end{array}$ & $\begin{array}{c}\text { Microvessel density } \\
\text { and endothelial cell } \\
\text { proliferation } \uparrow ; \\
\text { BDNF, eNOS and } \\
\text { VEGFs } \uparrow\end{array}$ & $\begin{array}{c}\text { Prompts neuro } \\
\text { behavioral recovery } \\
\text { and angiogenesis. } \\
\text { Reduces infarct } \\
\text { volume. }\end{array}$ \\
\hline $\begin{array}{l}\text { Ay et al., } \\
2016\end{array}$ & $\begin{array}{l}\text { Rats, MCAO } \\
\text { (right) }\end{array}$ & $\begin{array}{c}\text { tcVNS } \\
\text { (gammacore; } \\
\text { electrocore, LLC). }\end{array}$ & $\begin{array}{l}30 \text { min } \\
\text { post- } \\
\text { stroke }\end{array}$ & $\begin{array}{c}25 \mathrm{~Hz}, 1 \mathrm{~ms}, 5 \mathrm{kHz} \\
12 \mathrm{~V} \text { sine waves }\end{array}$ & $\begin{array}{l}\text { Right vagus } \\
\text { nerve in the } \\
\text { neck }\end{array}$ & $60 \mathrm{~min}$ & $\begin{array}{l}\text { Decreaselba-1, } \\
\text { CD68, and TNF- } \alpha \\
\text { positive cells and } \\
\text { increase the number } \\
\text { of HMGB1 positive } \\
\text { cells. }\end{array}$ & $\begin{array}{l}\text { Reduces infarct } \\
\text { volume. Improves } \\
\text { neurological score. } \\
\text { Inhibits } \\
\text { ischemia-induced } \\
\text { immune activation. }\end{array}$ \\
\hline
\end{tabular}

of tight junction proteins (TJPs). Matrix metalloproteinases (MMPs) are degrading enzymes that disrupt TJPs, leading to $\mathrm{BBB}$ disruption during ischemic stroke. In the ischemic hemisphere, taVNS inhibited BBB breakdown, as evidenced by decreases in TJP cleavage, ZO-1, occludin, and claudin5 in endothelial cells. Additionally, it protected tight junction 
proteins in microvessels from disruption and reduced MMP2/9 expressions in astrocytes around compromised vessels (Yang et al., 2018). In addition, taVNS improved BBB integrity after cerebral cortex microinfarcts as well as in rat models of cortical dysplasia and traumatic brain injury, indicating that it may be useful in the effects on $\mathrm{BBB}$ after ischemic stroke.

\section{Inhibiting Neuroinflammation}

Researchers believe that VNS can potentially modulate inflammation via a broader vagal neural network (Yuan and Silberstein, 2016). Recent studies suggest that VNS may act as a neuromodulator to activate certain innate, protective pathways in the central nervous system (CNS). VNS may exert its anti-inflammatory properties in a variety of diseases through its afferent fibers (activating the HPA pathway) and efferent fibers (activating the CAP pathway).

The vagus nerve system suppresses the release of proinflammatory cytokines. It was found that VNS reduced plasma levels of $\mathrm{TNF} \alpha$, IL-1 $\beta$, IL- 6 , and MPO in colitis rats through the autonomic neural pathway (Sun et al., 2013). There have been animal and clinical studies exploring the efficacy of $\mathrm{nVNS}$ in the treatment of inflammation. A study found that taVNS reduced IL- 6 and TNF- $\alpha$ release and prevented endotoxemia in mice (Hong et al., 2019). Lerman et al. (2016) found that tcVNS reduced levels of cytokines and chemokines in the blood of healthy people. Meanwhile, Clancy et al. (2014) reported that taVNS decreased sympathetic nerve activity in healthy people.

Through alpha-7 nicotinic acetylcholine receptors ( $\alpha 7 \mathrm{nAChRs),} \mathrm{central} \mathrm{immune} \mathrm{activation} \mathrm{(e.g.,} \mathrm{macrophage}$ accumulation and microglial activation) can influence acetylcholine levels and cause anti-inflammatory effects (Kalkman and Feuerbach, 2016). The $\alpha 7 \mathrm{nAChR}$ subunit is required for the CAP to limit cytokine production, according to Wang et al. (2003). The cholinergic anti-inflammatory response is induced by the $\alpha 7 \mathrm{nAChR}$. Acetylcholine is released when the vagus nerve is stimulated, inhibiting the anti-inflammatory pathway via the $\alpha 7 \mathrm{nAChR}$ on activated macrophages and other cytokine-producing cells. Finally, TNF and other proinflammatory cytokines that play a role in inflammation are suppressed (Oke and Tracey, 2009). Recent studies have also found that taVNS has anti-inflammatory effects in both the peripheral and central nervous systems, which are mediated through $\alpha 7 n$ AChRs (Zhao et al., 2012; Corsi-Zuelli et al., 2017). taVNS has also been reported to have neuroprotective effects against ischemic cerebral injuries via an anti-inflammatory mechanism (Li et al., 2020b).

Microglia are central nervous system resident macrophages that perform a variety of tasks such as synaptic organization, phagocytosis of apoptotic cells, and neuronal excitability regulation (Sasaki, 2017; Baig et al., 2022). Ischemia triggerS resting microglia to the M1 phenotype causing damage to functioning neural cells including neurons and astrocytes ( $\mathrm{Hu}$ et al., 2012). Activation of microglia to the M2 phenotype, on the other hand, can stop the inflammatory process by producing anti-inflammatory cytokines like IL-4 and IL-10
(Hu et al., 2012; Liu et al., 2016; Zhao X.-P. et al., 2019). As a result, microglial M2 polarization could be a new target for fighting inflammation after cerebral I/R injury. Zhao X.-P. et al., 2019) demonstrated that tcVNS attenuated cerebral ischemic injury by promoting microglial M2 polarization. Intranasal administration of recombinant IL-17A dampened the tcVNS induced M2 polarization of microglia and its neuroprotective effects, which suggests that the effect of tcVNS might occur through IL-17A signaling inhibition. tcVNS inhibits microglia activation and normalizes altered cytokine levels after MCAO by reducing the number of Iba-1, CD68, and TNF- $\alpha$ positive cells and increasing HMGB1 positive cells (Ay et al., 2016). These findings underline that anti-inflammatory mechanisms play an important role in ischemic neuroprotection by $\mathrm{nVNS}$.

\section{Facilitating Post-stroke Axonal Plasticity}

Axonal plasticity plays an important role in neurofunctional recovery after stroke. The neurofunctional recovery that occurs in the days to weeks following an ischemic stroke appears to be linked to axonal plasticity including axonal regeneration and reorganization (Liu et al., 2015; Bu et al., 2021). taVNS treatment enhanced $\alpha 7 \mathrm{nAchR}$ expression in the ischemic cortex. And ischemic rats treated with taVNS demonstrated improved axonal plasticity (regeneration and reorganization of axons), in accordance with elevated levels of $\mathrm{BDNF} / \mathrm{cAMP} / \mathrm{PKA} / \mathrm{p}-\mathrm{CREB}$ pathway members. Thus, taVNS could effectively boost axonal plasticity in the brain after I/R injury while improving neurofunctional recovery (Li et al., 2020b).

\section{Reducing Spreading Depolarizations}

Spreading depolarizations (SDs) are sudden and sustained gray matter depolarizations that can occur in a variety of brain states, ranging from healthy brain tissue, such as the migraine aura, to different areas of an ischemic brain, such as the severely energy-depleted infarct core and its surrounding moderately ischemic tissue (Dreier and Reiffurth, 2015). SDs are caused by the failure of the sodium pump in the penumbra aftera $\mathrm{n}$ ischemic stroke, and they create cytotoxic edema, disrupt blood flow, and result in infarction of viable tissue, as well as affecting neuronal survival and outcome (Dreier, 2011; Rakers and Petzold, 2017; Dreier et al., 2018; Baig et al., 2022). Furthermore, they are thought to play a role in the development of ionic and vasogenic edema at later stages of ischemia (Dreier et al., 2018; Mestre et al., 2020). As a result, in experimental models and clinical cases of stroke and other acute neurological disorders, SDs are among the most important contributors to infarct generation, cell death, and injury expansion (Lauritzen et al., 2011; Dreier and Reiffurth, 2015). Lindemann et al. (2020) discovered that delivering $\mathrm{nVNS}$ or iVNS during permanent MCAO significantly reduced the frequency of SDs in the cortical peri-infarct area compared to sham VNS, without affecting relative blood flow changes, blood pressure, heart rate, or breathing rate. They hypothesize that either nVNS or iVNS could be a safe and effective intervention for reducing the clinical burden of SD waves in stroke. 


\section{CLINICAL TRIALS TO ASSESS SAFETY AND EFFICACY OF NON-INVASIVE VAGUS NERVE STIMULATION AFTER CHRONIC/SUBACUTE ISCHEMIC STROKE}

In our review, we found four studies and one case report that investigated the influence of nVNS on upper-limb motor function, sensory function, and sleep disturbance after stroke. Among which, four studies included chronic stroke patients (Capone et al., 2017; Redgrave J.N. et al., 2018; Baig et al., 2019; Zhao B. et al., 2019) except one study included subacute ischemic stroke patients (Wu et al., 2020). Here, we summarized the mainly functional improvement, parameters, side effects and future directions of $\mathrm{nVNS}$ in clinical studies on stroke.

In addition, several recently completed and ongoing clinical studies are focused on the safety and effects of nVNS on stroke (Baig et al., 2022). Especially some studies are focused on acute or subacute stroke (NCT03733431; NCT04050501; NCT03292159; Clinicaltrials.gov). Instruments and procedures (MRI, CT perfusion, EMG, or force coupled to a computer monitor) that can help quantify the findings have been utilized in several studies in addition to the generally used scale for outcome evaluation. The findings should help us better understand the effectiveness, adverse effects, and ideal settings of nVNS, as well as how nVNS influences stroke.

\section{Non-invasive Vagus Nerve Stimulation Combined With Rehabilitation Improves Upper Limb Function After Chronic Stroke}

It is generally accepted that upper extremity impairment as one of the results of stroke has a deep impact on quality of life, but the clinical application of the treatment may not readily be seen until after stroke. Studies have shown that iVNS paired with rehabilitation significantly improves forelimb strength and speed in models of ischemia and hemorrhage in rats (Hiraki et al., 2012; Hays et al., 2014, 2016; Khodaparast et al., 2016). Clinical studies showed that paired rehabilitation with VNS improves motor function in patients suffering from chronic strokes. The FuglMeyer Assessment-Upper Extremity (FMA-UE) score of stroke patients after iVNS was clearly higher than the score of pure rehab patients who did not receive iVNS (Dawson et al., 2020). Significant improvements in the Wolf Motor Function Test (both in terms of function and timing), Box and Block Test and NineHole Peg Test has also been observed (Dawson et al., 2020). Similar results have also been reported in stroke patients treated with nVNS. Redgrave J.N. et al. (2018) conducted a pilot study combining taVNS with post-stroke upper limb rehabilitation in 18 sessions $(1 \mathrm{~h})$, showing improvement in motor function in the pilot study. While Redgrave and Baig used therapists to conduct rehabilitation training, Capone et al. (2017) have reported that taVNS combined with robot-assisted rehabilitation may be able to promote mild improvements in arm function and promote long-term benefits for stroke recovery.
Motor Activated Auricular Vagus Nerve Stimulation (MAAVNS) was devised as a closed-loop solution to the parametric problem (Cook et al., 2020). It combines taVNS with motor activity by using pulses at $25 \mathrm{~Hz}$ for $500 \mathrm{~s}$ during a focused motor task (Cook et al., 2020). It has been shown to be an effective neurorehabilitation tool and in early studies has shown promise in helping neonates learn motor skills (Badran et al., 2018, 2020). It is being explored further to facilitate stroke rehabilitation in adults. Therefore, the continued development of nVNS may radically change the field and potentially remove the barrier of surgery for many patient populations.

\section{Non-invasive Vagus Nerve Stimulation Improving Sensory Recovery After Chronic Stroke}

Stroke survivors with sensory impairments tend to recover less functionally after their injuries. A long-term follow-up study found iVNS combined with tactile therapy improved sensory function in a man suffering from the severe sensory decline in his left hand and arm (Meyers et al., 2018). This may be related to increased neuroplasticity throughout the brain. Following the study, the authors speculated that combining VNS with sensory stimulation can be an alternative method for promoting neuroplasticity and sensory recovery for chronic stroke patients. However, this was based on only one case study. After that, Baig et al. reported the impact of taVNS paired with repetitive motor task practice on sensory recovery in a cohort of chronic stroke patients. An average of 18 sessions $(1 \mathrm{~h} /$ session) were given over 6 weeks to twelve participants who were $>3$ months post-ischemic stroke and would still have residual upper limb weakness. The repetition of functional arm movements concurrently with the taVNS at the maximum level of intensity is 300 repetitions. The UFM (Upper Limb Fugl-Meyer) assessment was used to assess the light touch and proprioception of the upper limb at baseline and during post-intervention. Seven out of 11 participants (64\%) who had sensory impairment at baseline regained some sensation after the intervention. Patients with the greatest improvement in motor function had the greatest increase in UFM sensation.

There is a possibility that the improvements in proprioception observed in subjects could be explained by an improvement in strength and range of motion achieved through upper limb tasks facilitated by taVNS. As a result of the increased range of joint movements, it is possible that the increased sensory feedback from the affected limb increased neuroplasticity in the cortical sensory networks. When combined with the correlation between improved motor function and sensory feedback, it is possible to hypothesize that motor and sensory recovery are positive feedback loops that mutually enhance one another.

\section{Non-invasive Vagus Nerve Stimulation Treating Post-stroke Insomnia After Chronic Stroke}

Patients with cerebrovascular disease are often affected by poststroke insomnia (PSI). Approximately $37-59 \%$ of patients with stroke complain about insomnia (Duss et al., 2018). Studies 
suggest that insomnia is also associated with an increased risk of morbidity from cardiocerebrovascular disease as well as a reduced outcome from stroke. It has been proved that taVNS is effective in treating depression with insomnia and primary insomnia (Liu et al., 2020). A case report by Zhao B. et al. (2019) examined the effectiveness and neuromechanics of taVNS in PSI patients. BOLD-fMRI was carried out before and after 4 weeks of taVNS. A 4-week taVNS intensive treatment produced significant improvement in insomnia symptoms. Falling asleep time was reduced to less than $30 \mathrm{~min}$, and sleep duration was increased to $7 \mathrm{~h}$. The therapeutic effect was still observed 3 months after treatment. PSQI scores dropped from 13 to 8 points.

Based on the association of the basal ganglia with the frontal lobe and thalamus, a reduced functional connectivity in the striatum and thalamus may suggest an emotional circuit disorder. Following taVNS treatment, posterior cingulate cortex and regions of basal ganglia associated with emotion showed increased functional connectivity. This case study provides evidence that taVNS therapy may provide a new, portable, selfmanaged, and safe technique for the treatment of PSI patients.

\section{Clinical Trials to Assess Safety and Efficacy of Non-invasive Vagus Nerve Stimulation After Subacute Ischemic Stroke}

Researchers recently published a randomized pilot study exploring the safety and effectiveness of taVNS in treating patients with subacute ischemic stroke. In this study, 21 patients with strokes in the acute or subacute phase (between 0.5 and 3 months post onset) were included (Wu et al., 2020). At the endpoint, there were significantly greater improvements in FMAU, FIM, and WMFT scores in the taVNS group compared with the sham-taVNS group. Moreover, the taVNS group obtained a significantly higher improvement of FMA-U score as compared with the sham-taVNS group at 4and 12 weeks. Only one adverse event related to contact with the auricular skin electrodes was noted. In the present study, taVNS proved to have a beneficial effect on the rehabilitation of upper limb motor function in patients with subacute strokes. nVNS may be able to reduce ischemic brain injury as it can be easily applied within a nonhospital setting early after stroke thanks to its relatively small therapeutic window.

\section{Side Effects of Non-invasive Vagus Nerve Stimulation}

It has been shown that the nVNS was safe and well-tolerated, and those adverse events were very rare (Capone et al., 2017; Redgrave J.N. et al., 2018; Baig et al., 2019; Zhao B. et al., 2019; Wu et al., 2020). Redgrave J. et al. (2018) published a systematic review of the safety and tolerability of taVNS. Itching and redness (16.7\%) around the stimulation site are common side effects, as are tingling and pain in the area (Redgrave J. et al., 2018). Some less common side effects have been noted in $<1 \%$ of the study participants, including nausea and vomiting (Schulz-Stübner and Kehl, 2011; Kreuzer et al., 2014; Jacobs et al., 2015; Yuan and Silberstein, 2016), headache (Stefan et al., 2012;
Kreuzer et al., 2014; Gaul et al., 2016; Yuan and Silberstein, 2016; Baig et al., 2019), facial drooping (Goadsby et al., 2014; Yuan and Silberstein, 2016), dizziness (Jacobs et al., 2015; Gaul et al., 2016; Liu et al., 2018; Baig et al., 2019), vocal hoarseness (Stefan et al., 2012; Goadsby et al., 2014).

In addition, due to the vagus nerve's influence on cardiac activity, researchers closely monitored HR and BP during nVNS sessions in to detect any potential cardiovascular harm. The HR and systolic blood pressure (SBP) do not show significant prepost differences. All cardiovascular parameters did not change significantly throughout the treatment. Heart palpitations were reported in one research (Bauer et al., 2016). According to the systematic review by Redgrave J. et al. (2018), 7/1322 participants in total reported cardiac side effects such as palpitations, arrhythmia, bradycardia, and hypotension. Steyn et al. (2013) found that the mean heart rate in four participants with asthma decreased from 106 to 85 beats per minute following nVNS. However, all participants experienced no symptoms following the procedure. Symptomatic bradycardia was observed in a male volunteer who collapsed with bradycardia and hypotension after receiving bilateral conchal taVNS $(2-100 \mathrm{~Hz}$, pulse width $0.2 \mathrm{~ms})$ in addition to a painful stimulus (Laqua et al., 2014). Kreuzer et al. (2012) reported two cases of cardiac arrhythmia (left bundle branch block and sinus arrhythmia), in their retrospective assessment of the cardiac safety of taVNS. No work has yet examined the relationship between stimulation parameters or dose and the rate of side effects experienced, which should be a priority of future research in the area, and clear documentation of both side effects and stimulation parameters is crucial to observe any trends.

\section{Stimulation Parameters}

For VNS, setting the optimal stimulation parameters has a huge impact on clinical efficacy. Morrison et al. (2021) found that stimulation intensity affects motor cortex plasticity. Many factors, such as the stimulation site and side, electrode and waveform configuration, continuous stimulation or pulsesynchronous stimulation, titration protocols, current amplitude and frequency, and stimulation on-and-off time can impact the clinical efficacy of VNS (De Ferrari and Schwartz, 2011). According to Helmstaedter et al. (2001), the effectors of stimulation parameters and the resulting direction of VNS's cognitive effects appear to be highly constrained by stimulation parameters. The timing and amount of VNS therapy also play a crucial role in maximizing its therapeutic benefits (Meyers et al., 2018; Nuntaphum et al., 2018).

Due to the fact that studies have been done with participants with different clinical conditions and with diverse stimulation parameters, it is hard to determine an ideal stimulation site for any specific disease (Goadsby et al., 2014; Gaul et al., 2016; Liu et al., 2018; Martelletti et al., 2018). Despite the lack of consensus on ideal parameters, $\mathrm{nVNS}$ researchers carried out human clinical trials using parameters similar to those administered in cervically implanted VNS analogs.

Here are the specific parameters of stimulation for nVNS in several studies (Table 3). Most studies used the left auricular branch of the vagus nerve as the stimulated sites, except one 
TABLE 3 | Stimulation location, parameters, therapeutic effects, and side effects for all studies assessing the efficacy of nVNS in patients with stroke.

\begin{tabular}{|c|c|c|c|c|c|c|c|c|}
\hline Authors & Study groups & $\begin{array}{l}\text { Stimulation sites } \\
\text { and device }\end{array}$ & $\begin{array}{l}\text { Phase of } \\
\text { stroke }\end{array}$ & Paired & Parameter settings & $\begin{array}{c}\text { nVNS } \\
\text { duration }\end{array}$ & $\begin{array}{c}\text { Therapeutic } \\
\text { effects }\end{array}$ & Side effects \\
\hline $\begin{array}{l}\text { Wu et al., } \\
2020\end{array}$ & $\begin{array}{l}\text { taVNS/sham } \\
\text { group; } \\
\text { Randomized } \\
\text { pilot study }\end{array}$ & $\begin{array}{c}\text { taVNS; left ear } \\
\text { concha; bhd-1a } \\
\text { transcutaneous } \\
\text { electrical } \\
\text { stimulation therapy } \\
\text { instrument (Bohua, } \\
\text { china). }\end{array}$ & $\begin{array}{c}\text { Subacute } \\
\text { ischemic stroke }\end{array}$ & $\begin{array}{l}\text { taVNS paired with } \\
\text { conventional } \\
\text { rehabilitation } \\
\text { training }\end{array}$ & $\begin{array}{c}20 \mathrm{~Hz} \text {; } 0.3 \mathrm{~ms} \text {; lasting } \\
30 \text { s each time, } \\
\text { stimulating once } \\
\text { every } 5 \mathrm{~min} \text {; } \\
\text { Mean stimulation } \\
\text { intensity } 1.66 \mathrm{ma}\end{array}$ & 15 days. & $\begin{array}{l}\text { Improves upper } \\
\text { limb motor } \\
\text { function }\end{array}$ & Skin redness \\
\hline $\begin{array}{l}\text { Redgrave } \\
\text { J.N. et al., } \\
2018\end{array}$ & $\begin{array}{l}\text { Feasibility study } \\
\text { with no control } \\
\text { group. }\end{array}$ & $\begin{array}{l}\text { TaVNS; left ear } \\
\text { concha; Nemos } \\
\text { (cerbomed) }\end{array}$ & $\begin{array}{c}\text { Chronic stroke. } \\
3 \text { months } \\
\text { post-stroke }\end{array}$ & $\begin{array}{l}\text { taVNS paired with } \\
\text { upper limb } \\
\text { repetitive } \\
\text { task-specific } \\
\text { practice }\end{array}$ & $\begin{array}{c}25 \mathrm{~Hz} ; 0.1 \mathrm{~ms} ; \\
\text { Median stimulation } \\
\text { intensity } 1.4 \mathrm{~mA}\end{array}$ & $\begin{array}{c}3 \text { times a week, } \\
\text { over } 6 \text { weeks }\end{array}$ & $\begin{array}{l}\text { Improves upper } \\
\text { limb motor } \\
\text { function }\end{array}$ & $\begin{array}{l}\text { Light- } \\
\text { headedness in } \\
\text { one } \\
\text { Participant and } \\
\text { general tiredness } \\
\text { and fatigue in two }\end{array}$ \\
\hline $\begin{array}{l}\text { Baig et al., } \\
2019\end{array}$ & $\begin{array}{c}\text { Feasibility study } \\
\text { with no control } \\
\text { group. }\end{array}$ & $\begin{array}{l}\text { TaVNS; left ear } \\
\text { concha; Nemos } \\
\text { (cerbomed) }\end{array}$ & $\begin{array}{c}\text { Chronic stroke. } \\
3 \text { months } \\
\text { post-stroke }\end{array}$ & $\begin{array}{l}\text { taVNS paired with } \\
\text { repetitive upper } \\
\text { limb task training }\end{array}$ & $\begin{array}{c}25 \mathrm{~Hz} ; 0.1 \mathrm{~ms} ; \\
\text { Median stimulation } \\
\text { intensity } 1.4 \mathrm{~mA}\end{array}$ & $\begin{array}{c}3 \text { times a week, } \\
\text { over } 6 \text { weeks }\end{array}$ & $\begin{array}{l}\text { Promotes motor } \\
\text { and sensory } \\
\text { rehabilitation }\end{array}$ & None reported \\
\hline $\begin{array}{l}\text { Capone } \\
\text { et al., } 2017\end{array}$ & $\begin{array}{c}\text { Real or sham } \\
\text { tVNS } \\
\text { associated with } \\
\text { Robot-assisted } \\
\text { therapy. }\end{array}$ & $\begin{array}{l}\text { taVNS; left ear } \\
\text { concha; } \\
\text { Twister-ebm }\end{array}$ & $\begin{array}{l}\text { Chronic stroke, } \\
\text { ischemic or } \\
\text { hemorrhagic }\end{array}$ & $\begin{array}{l}\text { taVNS paired with } \\
\text { robot-assisted } \\
\text { therapy }\end{array}$ & $\begin{array}{c}20 \mathrm{~Hz} ; 0.3 \mathrm{~ms} \\
\text {,lasting } 30 \mathrm{~s} \text { each } \\
\text { time, stimulating once } \\
\text { every } 5 \text { min } \\
\text { Mean stimulation } \\
\text { intensity } 2.0-4.5 \mathrm{~mA}\end{array}$ & $\begin{array}{l}10 \text { working } \\
\text { days. }\end{array}$ & $\begin{array}{l}\text { Improves upper } \\
\text { limb function }\end{array}$ & None reported \\
\hline $\begin{array}{l}\text { Zhao B. } \\
\text { et al., } 2019\end{array}$ & Case report & $\begin{array}{l}\text { taVNS; bilateral } \\
\text { auricular concha } \\
\text { areas; device not } \\
\text { mentioned }\end{array}$ & $\begin{array}{c}7 \text { months post- } \\
\text { hemorrhagic } \\
\text { stroke }\end{array}$ & None & $\begin{array}{l}20 \mathrm{~Hz} \text {; less than } \\
1 \mathrm{~ms} ; \\
\text { Intensity 4-6 mA }\end{array}$ & $\begin{array}{c}30 \text { min, twice a } \\
\text { day, } 4 \text { weeks }\end{array}$ & $\begin{array}{l}\text { Alleviates } \\
\text { post-stroke } \\
\text { insomnia }\end{array}$ & None reported \\
\hline
\end{tabular}

case report chose bilateral auricular branches of the vagus nerve to stimulate. According to researchers, since vagal fibers to the heart are supposed to originate from the right side, only the left ear was stimulated to reduce the risk of cardiac side effects. A common frequency of 20 or $25 \mathrm{~Hz}$ is used in these studies. It is common for the stimulation current to be set according to a subject's sensitivity or just below their pain threshold (Frangos et al., 2015; Lerman et al., 2016; Yakunina et al., 2018; Sclocco et al., 2020; Yakunina and Nam, 2021). Studies gradually raised stimulation intensity by $0.1 \mathrm{~mA}$ increments until the maximum level reported by participants (Redgrave J.N. et al., 2018). The intensity of stimulation ranged between 0.5 and $6 \mathrm{~mA}$. Another study adjusted stimulation intensity to levels above detection thresholds and below pain thresholds (Capone et al., 2017). The range is similar to those reported in other diseases, Stimulation amplitudes vary over a wide range [from $0.5 \mathrm{~mA}$ (Jongkees et al., 2018) to $12 \mathrm{~mA}$ (Trevizol et al., 2016)]. The amplitude or amount, of energy delivered to tissues, is also unknown despite current values for electric motors being reported, due to the significant effect of electrode and tissue impedance and the need for precise placement. In addition, the electrochemistry of the stimulation electrode has a significant impact on the maximum current tolerance of the participant, without a doubt.

\section{CONCLUSION AND FUTURE DIRECTION}

In this review, we reviewed current animal and clinical researches on non-invasive vagus nerve stimulation on cerebral stroke, emphasizing the outcomes, underlying mechanisms, stimulation parameters, sites of stimulation, and side effects.

The development of neuroscience has led to a new type of intervention, neuromodulation therapy, that targets the nervous system to achieve therapeutic results. Several studies have shown that $\mathrm{nVNS}$ affects the same brain regions and yields therapeutic effects similar to iVNS (Terré and Mearin, 2009; Van Leusden et al., 2015). Since nVNS is non-invasive, it has been receiving special attention in basic, clinical, and translational research for its benefits which are comparable to those of iVNS, ease of use, and reduced side effects, In addition, it is more accessible. Auricular and cervical branches of the vagus nerve are most commonly targeted by nVNS.

As nVNS continues to emerge as a promising treatment in stroke, there is still a lot to be done and a large number of literatures to be improved. Several studies have confirmed the effect of nVNS on stroke rehabilitation, however, most of the current studies focused on upper limb function, and future studies need to focus on the improvement of other functions post-stroke, such as cognition impairment, dysphagia, aphasia, and intestinal dysfunction. There is a lack of large sample RCT studies, and therefore, no strong evidence on the role of nVNS in stroke rehabilitation.

Rehabilitation effects are being demonstrated in stroke. The parameters and protocols of most of the described methods vary enormously, so there is no clear evidence on the best location to apply nVNS or the stimulation parameters that will provide the most therapeutic benefit. As nVNS research grows, we need to take a historical perspective into account and further optimize 
the parameter space. In addition, study results should also be analyzed to determine the frequency of treatments, the number of doses per day, and the degree of treatment tolerance.

The precise mechanism by which nVNS exerts its therapeutic effects is still unclear. We need further studies examining the mechanical basis of nVNS to facilitate our future trials. A systematic study must be conducted to reveal the precise mechanism of action and ideal stimulation modalities of nVNS if it is to reach its full potential as a non-invasive and clinically relevant therapy. Future investigations should not be restricted by past hypotheses about the effects of nVNS on neural activation and function.

Most studies have only a small sample, some with only one participant. This makes it difficult to determine whether the findings or proposed pathways can be generalized. In order to avoid the risk of having extreme or biased results, studies with a large sample size are necessary. Further standard stimulation methods of nVNS combine electrophysiology and imaging evaluation methods are needed to reduce subjective bias during training and devise more effective rehabilitation strategies for stroke.

\section{REFERENCES}

Alrafiah, A., Alofi, E., Almohaya, Y., Hamami, A., Qadah, T., Almaghrabi, S., et al. (2021). Angiogenesis biomarkers in ischemic stroke patients. J. Inflamm. Res. 14, 4893-4900. doi: 10.2147/JIR.S331868

Ay, I., Nasser, R., Simon, B., and Ay, H. (2016). Transcutaneous cervical vagus nerve stimulation ameliorates acute ischemic injury in rats. Brain Stimulat. 9, 166-173. doi: 10.1016/j.brs.2015.11.008

Ay, I., Sorensen, A. G., and Ay, H. (2011). Vagus nerve stimulation reduces infarct size in rat focal cerebral ischemia: an unlikely role for cerebral blood flow. Brain Res. 1392, 110-115. doi: 10.1016/j.brainres.2011.03.060

Badran, B. W., Dowdle, L. T., Mithoefer, O. J., LaBate, N. T., Coatsworth, J., Brown, J. C., et al. (2018). Neurophysiologic effects of transcutaneous auricular vagus nerve stimulation (taVNS) via electrical stimulation of the tragus: a concurrent taVNS/fMRI study and review. Brain Stimulat. 11, 492-500. doi: 10.1016/j.brs. 2017.12.009

Badran, B. W., Jenkins, D. D., Cook, D., Thompson, S., Dancy, M., DeVries, W. H., et al. (2020). Transcutaneous auricular vagus nerve stimulation-paired rehabilitation for oromotor feeding problems in newborns: an open-label pilot study. Front. Hum. Neurosci. 14:77. doi: 10.3389/fnhum.2020.00077

Baig, S. S., Falidas, K., Laud, P. J., Snowdon, N., Farooq, M. U., Ali, A., et al. (2019). Transcutaneous auricular vagus nerve stimulation with upper limb repetitive task practice may improve sensory recovery in chronic stroke. J. Stroke Cerebrovasc. Dis. 28:104348. doi: 10.1016/j.jstrokecerebrovasdis.2019.104348

Baig, S. S., Kamarova, M., Ali, A., Su, L., Dawson, J., Redgrave, J. N., et al. (2022). Transcutaneous vagus nerve stimulation (tVNS) in stroke: the evidence, challenges and future directions. Auton. Neurosci. 237:102909. doi: 10.1016/j. autneu.2021.102909

Bauer, S., Baier, H., Baumgartner, C., Bohlmann, K., Fauser, S., Graf, W., et al. (2016). Transcutaneous vagus nerve stimulation (tVNS) for treatment of drugresistant epilepsy: a randomized, Double-Blind Clinical Trial (cMPsE02). Brain Stimulat. 9, 356-363. doi: 10.1016/j.brs.2015.11.003

Ben-Menachem, E. (2002). Vagus-nerve stimulation for the treatment of epilepsy. Lancet Neurol. 1, 477-482. doi: 10.1016/s1474-4422(02)00220-x

Ben-Menachem, E., Revesz, D., Simon, B. J., and Silberstein, S. (2015). Surgically implanted and non-invasive vagus nerve stimulation: a review of efficacy, safety and tolerability. Eur. J. Neurol. 22, 1260-1268. doi: 10.1111/ene.12629

Bermejo, P., López, M., Larraya, I., Chamorro, J., Cobo, J. L., Ordóñez, S., et al. (2017). Innervation of the human cavum conchae and auditory canal: anatomical basis for transcutaneous auricular nerve stimulation. Biomed Res. Int. 2017:7830919. doi: 10.1155/2017/7830919
In addition to helping avoid costly missed opportunities for reducing ischemic brain injury, nVNS may be able to reduce ischemic brain injury as it can be easily applied within a nonhospital setting early after stroke thanks to its relatively small therapeutic window.

\section{AUTHOR CONTRIBUTIONS}

QW conceived and supervised the project. LL and DW researched literature and wrote the manuscript. HP, LH, XS, and $\mathrm{CH}$ contributed to the manuscript revision. All authors contributed to the article and approved the submitted version.

\section{FUNDING}

This study was funded by National Key R\&D Program of China (Grant Nos. 2020YFC2008502 and 2020YFC2008505) and 1.3.5 Project for Disciplines of Excellence, West China Hospital, Sichuan University.

Brainin, M., Feigin, V. L., Norrving, B., Martins, S. C. O., Hankey, G. J., Hachinski, V., et al. (2020). Global prevention of stroke and dementia: the WSO Declaration. Lancet Neurol. 19, 487-488. doi: 10.1016/S1474-4422(20)30141-1

Bu, F., Munshi, Y., Furr, J. W., Min, J.-W., Qi, L., Patrizz, A., et al. (2021). Activation of neuronal Ras-related C3 botulinum toxin substrate 1 (Racl) improves poststroke recovery and axonal plasticity in mice. J. Neurochem. 157, 1366-1376. doi: $10.1111 /$ jnc.15195

Burger, A. M., and Verkuil, B. (2018). Transcutaneous nerve stimulation via the tragus: are we really stimulating the vagus nerve? Brain Stimulat. 11, 945-946. doi: 10.1016/j.brs.2018.03.018

Burger, A. M., Van Diest, I., Van der Does, W., Korbee, J. N., Waziri, N., Brosschot, J. F., et al. (2019). The effect of transcutaneous vagus nerve stimulation on fear generalization and subsequent fear extinction. Neurobiol. Learn. Mem. 161, 192-201. doi: 10.1016/j.nlm.2019.04.006

Butt, M. F., Albusoda, A., Farmer, A. D., and Aziz, Q. (2020). The anatomical basis for transcutaneous auricular vagus nerve stimulation. J. Anat. 236, 588-611. doi: $10.1111 /$ joa.13122

Cai, P. Y., Bodhit, A., Derequito, R., Ansari, S., Abukhalil, F., Thenkabail, S., et al. (2014). Vagus nerve stimulation in ischemic stroke: old wine in a new bottle. Front. Neurol. 5:107. doi: 10.3389/fneur.2014.00107

Capone, F., Miccinilli, S., Pellegrino, G., Zollo, L., Simonetti, D., Bressi, F., et al. (2017). Transcutaneous vagus nerve stimulation combined with robotic rehabilitation improves upper limb function after stroke. Neural Plast. 2017:7876507. doi: 10.1155/2017/7876507

Carreno, F. R., and Frazer, A. (2017). Vagal nerve stimulation for treatmentresistant depression. Neurother. J. Am. Soc. Exp. Neurother. 14, 716-727. doi: 10.1007/s13311-017-0537-8

Clancy, J. A., Mary, D. A., Witte, K. K., Greenwood, J. P., Deuchars, S. A., and Deuchars, J. (2014). Non-invasive vagus nerve stimulation in healthy humans reduces sympathetic nerve activity. Brain Stimulat. 7, 871-877. doi: 10.1016/j. brs.2014.07.031

Collins, L., Boddington, L., Steffan, P. J., and McCormick, D. (2021). Vagus nerve stimulation induces widespread cortical and behavioral activation. Curr. Biol. 31, 2088.e-2098.e. doi: 10.1016/j.cub.2021.02.049

Colzato, L. S., Ritter, S. M., and Steenbergen, L. (2018). Transcutaneous vagus nerve stimulation (tVNS) enhances divergent thinking. Neuropsychologia 111, 72-76. doi: 10.1016/j.neuropsychologia.2018.01.003

Cook, D. N., Thompson, S., Stomberg-Firestein, S., Bikson, M., George, M. S., Jenkins, D. D., et al. (2020). Design and validation of a closed-loop, motor-activated auricular vagus nerve stimulation (MAAVNS) system for neurorehabilitation. Brain Stimulat. 13, 800-803. doi: 10.1016/j.brs.2020.02.028 
Corsi-Zuelli, F. M., das, G., Brognara, F., Quirino, G. F., da, S., Hiroki, C. H., et al. (2017). Neuroimmune interactions in schizophrenia: focus on vagus nerve stimulation and activation of the alpha-7 nicotinic acetylcholine receptor. Front. Immunol. 8:618. doi: 10.3389/fimmu.2017.00618

Dawson, J., Engineer, N. D., Prudente, C. N., Pierce, D., Francisco, G., Yozbatiran, N., et al. (2020). Vagus nerve stimulation paired with upper-limb rehabilitation after stroke: one-year follow-up. Neurorehabil. Neural Repair 34, 609-615. doi: $10.1177 / 1545968320924361$

Dawson, J., Liu, C. Y., Francisco, G. E., Cramer, S. C., Wolf, S. L., Dixit, A., et al. (2021). Vagus nerve stimulation paired with rehabilitation for upper limb motor function after ischaemic stroke (VNS-REHAB): a randomised, blinded, pivotal, device trial. Lancet Lond. Engl. 397, 1545-1553. doi: 10.1016/S0140-6736(21) 00475-X

De Ferrari, G. M., and Schwartz, P. J. (2011). Vagus nerve stimulation: from preclinical to clinical application: challenges and future directions. Heart Fail. Rev. 16, 195-203. doi: 10.1007/s10741-010-9216-0

DeGiorgio, C. M., and Krahl, S. E. (2013). Neurostimulation for drug-resistant epilepsy. Continuum 19, 743-755. doi: 10.1212/01.CON.0000431397.61970.2b

Dreier, J. P. (2011). The role of spreading depression, spreading depolarization and spreading ischemia in neurological disease. Nat. Med. 17, 439-447. doi: $10.1038 / \mathrm{nm} .2333$

Dreier, J. P., and Reiffurth, C. (2015). The stroke-migraine depolarization continuum. Neuron 86, 902-922. doi: 10.1016/j.neuron.2015.04.004

Dreier, J. P., Lemale, C. L., Kola, V., Friedman, A., and Schoknecht, K. (2018). Spreading depolarization is not an epiphenomenon but the principal mechanism of the cytotoxic edema in various gray matter structures of the brain during stroke. Neuropharmacology 134, 189-207. doi: 10.1016/j.neuropharm. 2017.09.027

Duss, S. B., Brill, A.-K., Bargiotas, P., Facchin, L., Alexiev, F., Manconi, M., et al. (2018). Sleep-wake disorders in stroke-increased stroke risk and deteriorated recovery? An evaluation on the necessity for prevention and treatment. Curr. Neurol. Neurosci. Rep. 18:72. doi: 10.1007/s11910-018 $-0879-6$

Farmer, A. D., Strzelczyk, A., Finisguerra, A., Gourine, A. V., Gharabaghi, A., Hasan, A., et al. (2020). International consensus based review and recommendations for minimum reporting standards in research on transcutaneous vagus nerve stimulation (version 2020). Front. Hum. Neurosci. 14:568051. doi: 10.3389/fnhum.2020.568051

Frangos, E., Ellrich, J., and Komisaruk, B. R. (2015). Non-invasive access to the vagus nerve central projections via electrical stimulation of the external ear: fMRI evidence in humans. Brain Stimulat. 8, 624-636. doi: 10.1016/j.brs.2014. 11.018

Gaul, C., Diener, H.-C., Silver, N., Magis, D., Reuter, U., Andersson, A., et al. (2016). Non-invasive vagus nerve stimulation for PREVention and Acute treatment of chronic cluster headache (PREVA): a randomised controlled study. Cephalalgia Int. J. Headache 36, 534-546. doi: 10.1177/0333102415607070

Genheimer, H., Andreatta, M., Asan, E., and Pauli, P. (2017). Reinstatement of contextual conditioned anxiety in virtual reality and the effects of transcutaneous vagus nerve stimulation in humans. Sci. Rep. 7:17886. doi: 10. 1038/s41598-017-18183-3

Goadsby, P. J., Grosberg, B. M., Mauskop, A., Cady, R., and Simmons, K. A. (2014). Effect of noninvasive vagus nerve stimulation on acute migraine: an open-label pilot study. Cephalalgia Int. J. Headache 34, 986-993. doi: 10.1177/ 0333102414524494

Goodnick, P. J., Rush, A. J., George, M. S., Marangell, L. B., and Sackeim, H. A. (2001). Vagus nerve stimulation in depression. Expert Opin. Pharmacother. 2, 1061-1063. doi: 10.1517/14656566.2.7.1061

Groves, D. A., and Brown, V. J. (2005). Vagal nerve stimulation: a review of its applications and potential mechanisms that mediate its clinical effects. Neurosci. Biobehav. Rev. 29, 493-500. doi: 10.1016/j.neubiorev.2005.01.004

Guiraud, D., Andreu, D., Bonnet, S., Carrault, G., Couderc, P., Hagège, A., et al. (2016). Vagus nerve stimulation: state of the art of stimulation and recording strategies to address autonomic function neuromodulation. J. Neural Eng. 13:041002. doi: 10.1088/1741-2560/13/4/041002

Hays, S. A., Khodaparast, N., Hulsey, D. R., Ruiz, A., Sloan, A. M., Rennaker, R. L., et al. (2014). Vagus nerve stimulation during rehabilitative training improves functional recovery after intracerebral hemorrhage. Stroke 45, 3097-3100. doi: 10.1161/STROKEAHA.114.006654
Hays, S. A., Ruiz, A., Bethea, T., Khodaparast, N., Carmel, J. B., Rennaker, R. L., et al. (2016). Vagus nerve stimulation during rehabilitative training enhances recovery of forelimb function after ischemic stroke in aged rats. Neurobiol. Aging 43, 111-118. doi: 10.1016/j.neurobiolaging.2016.03.030

Helmstaedter, C., Hoppe, C., and Elger, C. E. (2001). Memory alterations during acute high-intensity vagus nerve stimulation. Epilepsy Res. 47, 37-42. doi: 10. 1016/s0920-1211(01)00291-1

Hiraki, T., Baker, W., and Greenberg, J. H. (2012). Effect of vagus nerve stimulation during transient focal cerebral ischemia on chronic outcome in rats. J. Neurosci. Res. 90, 887-894. doi: 10.1002/jnr.22812

Hong, G.-S., Zillekens, A., Schneiker, B., Pantelis, D., de Jonge, W. J., Schaefer, N., et al. (2019). Non-invasive transcutaneous auricular vagus nerve stimulation prevents postoperative ileus and endotoxemia in mice. Neurogastroenterol. Motil. 31:e13501. doi: 10.1111/nmo.13501

Hu, X., Li, P., Guo, Y., Wang, H., Leak, R. K., Chen, S., et al. (2012). Microglia/macrophage polarization dynamics reveal novel mechanism of injury expansion after focal cerebral ischemia. Stroke 43, 3063-3070. doi: 10.1161/ STROKEAHA.112.659656

Jacobs, H. I. L., Riphagen, J. M., Razat, C. M., Wiese, S., and Sack, A. T. (2015). Transcutaneous vagus nerve stimulation boosts associative memory in older individuals. Neurobiol. Aging 36, 1860-1867. doi: 10.1016/j.neurobiolaging. 2015.02.023

Jiang, Y., Li, L., Ma, J., Zhang, L., Niu, F., Feng, T., et al. (2016). Auricular vagus nerve stimulation promotes functional recovery and enhances the post-ischemic angiogenic response in an ischemia/reperfusion rat model. Neurochem. Int. 97, 73-82. doi: 10.1016/j.neuint.2016.02.009

Jongkees, B. J., Immink, M. A., Finisguerra, A., and Colzato, L. S. (2018). Transcutaneous Vagus Nerve Stimulation (tVNS) enhances response selection during sequential action. Front. Psychol. 9:1159. doi: 10.3389/fpsyg.2018.01159

Kalkman, H. O., and Feuerbach, D. (2016). Modulatory effects of $\alpha 7$ nAChRs on the immune system and its relevance for CNS disorders. Cell. Mol. Life Sci. 73, 2511-2530. doi: 10.1007/s00018-016-2175-4

Kaniusas, E., Kampusch, S., Tittgemeyer, M., Panetsos, F., Gines, R. F., Papa, M., et al. (2019). Current directions in the auricular vagus nerve stimulation i a physiological perspective. Front. Neurosci. 13:854. doi: 10.3389/fnins.2019. 00854

Khodaparast, N., Hays, S. A., Sloan, A. M., Fayyaz, T., Hulsey, D. R., Rennaker, R. L., et al. (2014). Vagus nerve stimulation delivered during motor rehabilitation improves recovery in a rat model of stroke. Neurorehabil. Neural Repair 28, 698-706. doi: 10.1177/1545968314521006

Khodaparast, N., Kilgard, M. P., Casavant, R., Ruiz, A., Qureshi, I., Ganzer, P. D., et al. (2016). Vagus nerve stimulation during rehabilitative training improves forelimb recovery after chronic ischemic stroke in rats. Neurorehabil. Neural Repair 30, 676-684. doi: 10.1177/1545968315616494

Kraus, T., Hösl, K., Kiess, O., Schanze, A., Kornhuber, J., and Forster, C. (2007). BOLD fMRI deactivation of limbic and temporal brain structures and mood enhancing effect by transcutaneous vagus nerve stimulation. J. Neural Transm. 1996, 1485-1493. doi: 10.1007/s00702-007-0755-z

Kreuzer, P. M., Landgrebe, M., Husser, O., Resch, M., Schecklmann, M., Geisreiter, F., et al. (2012). Transcutaneous vagus nerve stimulation: retrospective assessment of cardiac safety in a pilot study. Front. Psychiatry 3:70. doi: 10.3389/ fpsyt.2012.00070

Kreuzer, P. M., Landgrebe, M., Resch, M., Husser, O., Schecklmann, M., Geisreiter, F., et al. (2014). Feasibility, safety and efficacy of transcutaneous vagus nerve stimulation in chronic tinnitus: an open pilot study. Brain Stimulat. 7, 740-747. doi: 10.1016/j.brs.2014.05.003

Kuriakose, D., and Xiao, Z. (2020). Pathophysiology and treatment of stroke: present status and future perspectives. Int. J. Mol. Sci. 21:E7609. doi: 10.3390/ ijms21207609

Lanska, D. J. (2002). J.L. Corning and vagal nerve stimulation for seizures in the 1880s. Neurology 58, 452-459. doi: 10.1212/wnl.58.3.452

Laqua, R., Leutzow, B., Wendt, M., and Usichenko, T. (2014). Transcutaneous vagal nerve stimulation may elicit anti- and pro-nociceptive effects under experimentally-induced pain - a crossover placebo-controlled investigation. Auton. Neurosci. Basic Clin. 185, 120-122. doi: 10.1016/j.autneu.2014.07.008

Lauritzen, M., Dreier, J. P., Fabricius, M., Hartings, J. A., Graf, R., and Strong, A. J. (2011). Clinical relevance of cortical spreading depression in neurological disorders: migraine, malignant stroke, subarachnoid and 
intracranial hemorrhage, and traumatic brain injury. J. Cereb. Blood Flow Metab. 31, 17-35. doi: 10.1038/jcbfm.2010.191

Lee, K. B., Lim, S. H., Kim, K. H., Kim, K. J., Kim, Y. R., Chang, W. N., et al. (2015). Six-month functional recovery of stroke patients: a multi-time-point study. Int. J. Rehabil. Res. 38, 173-180. doi: 10.1097/MRR.0000000000000108

Lerman, I., Hauger, R., Sorkin, L., Proudfoot, J., Davis, B., Huang, A., et al. (2016). Noninvasive transcutaneous vagus nerve stimulation decreases whole blood culture-derived cytokines and chemokines: a randomized, blinded, healthy control pilot trial. Neuromodulation 19, 283-290. doi: 10.1111/ner.12398

Li, J., Zhang, K., Zhang, Q., Zhou, X., Wen, L., Ma, J., et al. (2020a). PPAR- $\gamma$ Mediates Ta-VNS-Induced angiogenesis and subsequent functional recovery after experimental stroke in rats. Biomed Res. Int. 2020:8163789. doi: 10.1155/ 2020/8163789

Li, J., Zhang, Q., Li, S., Niu, L., Ma, J., Wen, L., et al. (2020b). $\alpha 7$ nAchR mediates transcutaneous auricular vagus nerve stimulation-induced neuroprotection in a rat model of ischemic stroke by enhancing axonal plasticity. Neurosci. Lett. 730:135031. doi: 10.1016/j.neulet.2020.135031

Lindemann, J., Rakers, C., Matuskova, H., Simon, B. J., Kinfe, T., and Petzold, G. C. (2020). Vagus nerve stimulation reduces spreading depolarization burden and cortical infarct volume in a rat model of stroke. PLoS One 15:e0236444. doi: 10.1371/journal.pone.0236444

Liu, A., Rong, P., Gong, L., Song, L., Wang, X., Li, L., et al. (2018). Efficacy and safety of treatment with transcutaneous vagus nerve stimulation in 17 patients with refractory epilepsy evaluated by electroencephalogram, seizure frequency, and quality of life. Med. Sci. Monit. 24, 8439-8448. doi: 10.12659/MSM.91 0689

Liu, B., Li, L.-L., Tan, X.-D., Zhang, Y.-H., Jiang, Y., He, G.-Q., et al. (2015). Gadd45b mediates axonal plasticity and subsequent functional recovery after experimental stroke in rats. Mol. Neurobiol. 52, 1245-1256. doi: 10.1007/ s12035-014-8909-0

Liu, C.-H., Yang, M.-H., Zhang, G.-Z., Wang, X.-X., Li, B., Li, M., et al. (2020). Neural networks and the anti-inflammatory effect of transcutaneous auricular vagus nerve stimulation in depression. J. Neuroinflamm. 17:54. doi: 10.1186/ s12974-020-01732-5

Liu, X., Liu, J., Zhao, S., Zhang, H., Cai, W., Cai, M., et al. (2016). Interleukin-4 is essential for microglia/macrophage M2 polarization and long-term recovery after cerebral ischemia. Stroke 47, 498-504. doi: 10.1161/STROKEAHA.115. 012079

Lu, X.-X., Hong, Z.-Q., Tan, Z., Sui, M.-H., Zhuang, Z.-Q., Liu, H.-H., et al. (2017). Nicotinic acetylcholine receptor alpha7 subunit mediates vagus nerve stimulation-induced neuroprotection in acute permanent cerebral ischemia by a7nAchR/JAK2 pathway. Med. Sci. Monit. 23, 6072-6081. doi: 10.12659/msm. 907628

Ma, J., Zhang, L., He, G., Tan, X., Jin, X., and Li, C. (2016). Transcutaneous auricular vagus nerve stimulation regulates expression of growth differentiation factor 11 and activin-like kinase 5 in cerebral ischemia/reperfusion rats. J. Neurol. Sci. 369, 27-35. doi: 10.1016/j.jns.2016.08.004

Marin, J., Giffin, N., Consiglio, E., McClure, C., Liebler, E., and Davies, B. (2018). Non-invasive vagus nerve stimulation for treatment of cluster headache: early UK clinical experience. J. Headache Pain 19:114. doi: 10.1186/s10194-0180936-1

Martelletti, P., Barbanti, P., Grazzi, L., Pierangeli, G., Rainero, I., Geppetti, P., et al. (2018). Correction to: consistent effects of non-invasive vagus nerve stimulation (nVNS) for the acute treatment of migraine: additional findings from the randomized, sham-controlled, double-blind PRESTO trial. J. Headache Pain 19:120. doi: 10.1186/s10194-018-0949-9

Mertens, A., Raedt, R., Gadeyne, S., Carrette, E., Boon, P., and Vonck, K. (2018). Recent advances in devices for vagus nerve stimulation. Expert Rev. Med. Devices 15, 527-539. doi: 10.1080/17434440.2018.1507732

Mestre, H., Du, T., Sweeney, A. M., Liu, G., Samson, A. J., Peng, W., et al. (2020). Cerebrospinal fluid influx drives acute ischemic tissue swelling. Science 367:eaax7171. doi: 10.1126/science.aax7171

Meyers, E. C., Solorzano, B. R., James, J., Ganzer, P. D., Lai, E. S., Rennaker, R. L., et al. (2018). Vagus nerve stimulation enhances stable plasticity and generalization of stroke recovery. Stroke 49, 710-717. doi: 10.1161/ STROKEAHA.117.019202

Morris, G. L., Gloss, D., Buchhalter, J., Mack, K. J., Nickels, K., and Harden, C. (2013). Evidence-based guideline update: vagus nerve stimulation for the treatment of epilepsy: report of the guideline development subcommittee of the american academy of neurology. Epilepsy Curr. 13, 297-303. doi: 10.5698/15357597-13.6.297

Morrison, R. A., Hays, S. A., and Kilgard, M. P. (2021). Vagus nerve stimulation as a potential adjuvant to rehabilitation for post-stroke motor speech disorders. Front. Neurosci. 15:715928. doi: 10.3389/fnins.2021.715928

Nuntaphum, W., Pongkan, W., Wongjaikam, S., Thummasorn, S., Tanajak, P., Khamseekaew, J., et al. (2018). Vagus nerve stimulation exerts cardioprotection against myocardial ischemia/reperfusion injury predominantly through its efferent vagal fibers. Basic Res. Cardiol. 113:22. doi: 10.1007/s00395018-0683-0

Oke, S. L., and Tracey, K. J. (2009). The inflammatory reflex and the role of complementary and alternative medical therapies. Ann. N. Y. Acad. Sci. 1172, 172-180. doi: 10.1196/annals.1393.013

Peuker, E. T., and Filler, T. J. (2002). The nerve supply of the human auricle. Clin. Anat. 15, 35-37. doi: 10.1002/ca.1089

Pruitt, D. T., Schmid, A. N., Kim, L. J., Abe, C. M., Trieu, J. L., Choua, C., et al. (2016). Vagus nerve stimulation delivered with motor training enhances recovery of function after traumatic brain injury. J. Neurotrauma 33, 871-879. doi: 10.1089/neu.2015.3972

Raedt, R., Clinckers, R., Mollet, L., Vonck, K., El Tahry, R., Wyckhuys, T., et al. (2011). Increased hippocampal noradrenaline is a biomarker for efficacy of vagus nerve stimulation in a limbic seizure model. J. Neurochem. 117, 461-469. doi: 10.1111/j.1471-4159.2011.07214.x

Rakers, C., and Petzold, G. C. (2017). Astrocytic calcium release mediates periinfarct depolarizations in a rodent stroke model. J. Clin. Invest. 127, 511-516. doi: 10.1172/JCI89354

Redgrave, J. N., Moore, L., Oyekunle, T., Ebrahim, M., Falidas, K., Snowdon, N., et al. (2018). Transcutaneous auricular vagus nerve stimulation with concurrent upper limb repetitive task practice for poststroke motor recovery: a pilot study. J. Stroke Cerebrovasc. Dis. 27, 1998-2005. doi: 10.1016/j.jstrokecerebrovasdis. 2018.02.056

Redgrave, J., Day, D., Leung, H., Laud, P. J., Ali, A., Lindert, R., et al. (2018). Safety and tolerability of transcutaneous vagus nerve stimulation in humans; a systematic review. Brain Stimulat. 11, 1225-1238. doi: 10.1016/j.brs.2018.08. 010

Ruffoli, R., Giorgi, F. S., Pizzanelli, C., Murri, L., Paparelli, A., and Fornai, F. (2011). The chemical neuroanatomy of vagus nerve stimulation. J. Chem. Neuroanat. 42, 288-296. doi: 10.1016/j.jchemneu.2010.12.002

Sasaki, A. (2017). Microglia and brain macrophages: an update. Neuropathology 37, 452-464. doi: 10.1111/neup.12354

Schulz-Stübner, S., and Kehl, F. (2011). Treatment of persistent hiccups with transcutaneous phrenic and vagal nerve stimulation. Intensive Care Med. 37, 1048-1049. doi: 10.1007/s00134-011-2150-3

Sclocco, R., Garcia, R. G., Kettner, N. W., Fisher, H. P., Isenburg, K., Makarovsky, M., et al. (2020). Stimulus frequency modulates brainstem response to respiratory-gated transcutaneous auricular vagus nerve stimulation. Brain Stimulat. 13, 970-978. doi: 10.1016/j.brs.2020.03.011

Song, D., Zhang, X., Chen, J., Liu, X., Xue, J., Zhang, L., et al. (2019). Wnt canonical pathway activator TWS119 drives microglial anti-inflammatory activation and facilitates neurological recovery following experimental stroke. J. Neuroinflammation 16:256. doi: 10.1186/s12974-019-1660-8

Stefan, H., Kreiselmeyer, G., Kerling, F., Kurzbuch, K., Rauch, C., Heers, M., et al. (2012). Transcutaneous vagus nerve stimulation ( $t$-VNS) in pharmacoresistant epilepsies: a proof of concept trial. Epilepsia 53, e115-e118. doi: 10.1111/j.15281167.2012.03492.x

Steyn, E., Mohamed, Z., and Husselman, C. (2013). Non-invasive vagus nerve stimulation for the treatment of acute asthma exacerbations-results from an initial case series. Int. J. Emerg. Med. 6:7. doi: 10.1186/1865-1 380-6-7

Straube, A., Ellrich, J., Eren, O., Blum, B., and Ruscheweyh, R. (2015). Treatment of chronic migraine with transcutaneous stimulation of the auricular branch of the vagal nerve (auricular t-VNS): a randomized, monocentric clinical trial. J. Headache Pain 16:543. doi: 10.1186/s10194-015-0543-3

Sun, P., Zhou, K., Wang, S., Li, P., Chen, S., Lin, G., et al. (2013). Involvement of MAPK/NF- $\kappa \mathrm{B}$ signaling in the activation of the cholinergic anti-inflammatory pathway in experimental colitis by chronic vagus nerve stimulation. PLoS One 8:e69424. doi: 10.1371/journal.pone.0069424 
Sun, Z., Baker, W., Hiraki, T., and Greenberg, J. H. (2012). The effect of right vagus nerve stimulation on focal cerebral ischemia: an experimental study in the rat. Brain Stimulat. 5, 1-10. doi: 10.1016/j.brs.2011.01.009

Terré, R., and Mearin, F. (2009). Evolution of tracheal aspiration in severe traumatic brain injury-related oropharyngeal dysphagia: 1-year longitudinal follow-up study. Neurogastroenterol. Motil. 21, 361-369. doi: 10.1111/j.13652982.2008.01208.x

Thayer, J. F., Yamamoto, S. S., and Brosschot, J. F. (2010). The relationship of autonomic imbalance, heart rate variability and cardiovascular disease risk factors. Int. J. Cardiol. 141, 122-131. doi: 10.1016/j.ijcard.2009. 09.543

Thompson, S. L., O’Leary, G. H., Austelle, C. W., Gruber, E., Kahn, A. T., Manett, A. J., et al. (2021). A review of parameter settings for invasive and non-invasive vagus nerve stimulation (vns) applied in neurological and psychiatric disorders. Front. Neurosci. 15:709436. doi: 10.3389/fnins.2021.709436

Trevizol, A. P., Shiozawa, P., Taiar, I., Soares, A., Gomes, J. S., Barros, M. D., et al. (2016). Transcutaneous vagus nerve stimulation (taVNS) for major depressive disorder: an open label proof-of-concept trial. Brain Stimulat. 9, 453-454. doi: 10.1016/j.brs.2016.02.001

Trevizol, A., Barros, M. D., Liquidato, B., Cordeiro, Q., and Shiozawa, P. (2015). Vagus nerve stimulation in neuropsychiatry: targeting anatomybased stimulation sites. Epilepsy Behav. 51:18. doi: 10.1016/j.yebeh.2015. 07.009

Van Leusden, J. W. R., Sellaro, R., and Colzato, L. S. (2015). Transcutaneous Vagal Nerve Stimulation (tVNS): a new neuromodulation tool in healthy humans? Front. Psychol. 6:102. doi: 10.3389/fpsyg.2015.00102

Wang, H., Yu, M., Ochani, M., Amella, C. A., Tanovic, M., Susarla, S., et al. (2003). Nicotinic acetylcholine receptor alpha7 subunit is an essential regulator of inflammation. Nature 421, 384-388. doi: 10.1038/nature01339

Wang, Y., Zhan, G., Cai, Z., Jiao, B., Zhao, Y., Li, S., et al. (2021c). Vagus nerve stimulation in brain diseases: therapeutic applications and biological mechanisms. Neurosci. Biobehav. Rev. 127, 37-53. doi: 10.1016/j.neubiorev. 2021.04.018

Wang, Y., Li, S.-Y., Wang, D., Wu, M.-Z., He, J.-K., Zhang, J.-L., et al. (2021b). Transcutaneous auricular vagus nerve stimulation: from concept to application. Neurosci. Bull. 37, 853-862. doi: 10.1007/s12264-020-00619-y

Wang, J., Li, Y., Yu, H., Li, G., Bai, S., Chen, S., et al. (2021a). Dl-3-N-Butylphthalide promotes angiogenesis in an optimized model of transient ischemic attack in C57BL/6 Mice. Front. Pharmacol. 12:751397. doi: 10.3389/fphar.2021.751397

Wu, D., Ma, J., Zhang, L., Wang, S., Tan, B., and Jia, G. (2020). Effect and safety of transcutaneous auricular vagus nerve stimulation on recovery of upper limb motor function in subacute ischemic stroke patients: a randomized pilot study. Neural Plast. 2020:8841752. doi: 10.1155/2020/8841752

Yakunina, N., and Nam, E.-C. (2021). Direct and transcutaneous vagus nerve stimulation for treatment of tinnitus: a scoping review. Front. Neurosci. 15:680590. doi: 10.3389/fnins.2021.680590

Yakunina, N., Kim, S. S., and Nam, E.-C. (2017). Optimization of transcutaneous vagus nerve stimulation using functional MRI. Neuromodulation 20, 290-300. doi: $10.1111 /$ ner.12541

Yakunina, N., Kim, S. S., and Nam, E.-C. (2018). BOLD fMRI effects of transcutaneous vagus nerve stimulation in patients with chronic tinnitus. PLoS One 13:e0207281. doi: 10.1371/journal.pone.0207281
Yang, Y., Yang, L. Y., Orban, L., Cuylear, D., Thompson, J., Simon, B., et al. (2018). Non-invasive vagus nerve stimulation reduces blood-brain barrier disruption in a rat model of ischemic stroke. Brain Stimulat. 11, 689-698. doi: 10.1016/j. brs.2018.01.034

Young, A. H., Juruena, M. F., De Zwaef, R., and Demyttenaere, K. (2020). Vagus nerve stimulation as adjunctive therapy in patients with difficult-to-treat depression (RESTORE-LIFE): study protocol design and rationale of a realworld post-market study. BMC Psychiatry 20:471. doi: 10.1186/s12888-02002869-6

Yuan, H., and Silberstein, S. D. (2016). Vagus nerve and vagus nerve stimulation, a comprehensive review: part I. Headache 56, 71-78. doi: 10.1111/head.12647

Zhang, L., Ma, J., Jin, X., Jia, G., Jiang, Y., and Li, C. (2017). L-PGDS mediates vagus nerve stimulation-induced neuroprotection in a rat model of ischemic stroke by suppressing the apoptotic response. Neurochem. Res. 42, 644-655. doi: 10.1007/s11064-016-2121-8

Zhao, B., Li, L., Jiao, Y., Luo, M., Xu, K., Hong, Y., et al. (2019). Transcutaneous auricular vagus nerve stimulation in treating post-stroke insomnia monitored by resting-state fMRI: the first case report. Brain Stimulat. 12, 824-826. doi: 10.1016/j.brs.2019.02.016

Zhao, J.-J., Wang, Z.-H., Zhang, Y.-J., Wang, W.-J., Cheng, A.-F., Rong, P.-J., et al. (2022). The mechanisms through which auricular vagus nerve stimulation protects against cerebral ischemia/reperfusion injury. Neural Regen. Res. 17, 594-600. doi: 10.4103/1673-5374.320992

Zhao, X.-P., Zhao, Y., Qin, X.-Y., Wan, L.-Y., and Fan, X.-X. (2019). Non-invasive vagus nerve stimulation protects against cerebral ischemia/reperfusion injury and promotes microglial M2 polarization via interleukin-17A inhibition. J. Mol. Neurosci. 67, 217-226. doi: 10.1007/s12031-018-1227-7

Zhao, Y. X., He, W., Jing, X. H., Liu, J. L., Rong, P. J., Ben, H., et al. (2012). Transcutaneous auricular vagus nerve stimulation protects endotoxemic rat from lipopolysaccharide-induced inflammation. Evid. Based Complement. Altern. Med. 2012:627023. doi: 10.1155/2012/627023

Zulfiqar, U., Jurivich, D. A., Gao, W., and Singer, D. H. (2010). Relation of high heart rate variability to healthy longevity. Am. J. Cardiol. 105, 1181-1185. doi: 10.1016/j.amjcard.2009.12.022

Conflict of Interest: The authors declare that the research was conducted in the absence of any commercial or financial relationships that could be construed as a potential conflict of interest.

Publisher's Note: All claims expressed in this article are solely those of the authors and do not necessarily represent those of their affiliated organizations, or those of the publisher, the editors and the reviewers. Any product that may be evaluated in this article, or claim that may be made by its manufacturer, is not guaranteed or endorsed by the publisher.

Copyright (c) 2022 Li, Wang, Pan, Huang, Sun, He and Wei. This is an openaccess article distributed under the terms of the Creative Commons Attribution License (CC BY). The use, distribution or reproduction in other forums is permitted, provided the original author(s) and the copyright owner(s) are credited and that the original publication in this journal is cited, in accordance with accepted academic practice. No use, distribution or reproduction is permitted which does not comply with these terms. 